\title{
Water treatment with SODIS for riverine Communities
}

\author{
Nayandra Carvalho da Silva ${ }^{1}$, Maria Cecilia Rosinski Lima Gomes ${ }^{2}$
}

${ }^{1,2}$ Instituto de Desenvolvimento Sustentável Mamirauá (IDSM). Bolsista PIBIC do CNPq. Estrada do Bexiga, 3584. Tefé-AM.

Email: nayandracarvalho1@ hotmail.com, cecilia@mamiraua.org.br

Received: March 13th, 2017

Accepted: May 14th, 2017

Published: June 30th, 2017

Copyright $\bigcirc 2016$ by authors and Institute of Technology Galileo of Amazon (ITEGAM).

This work is licensed under the Creative Commons Attribution International License (CC BY 4.0).

http://creativecommons.org/lic enses/b y/4.0/ (c) (i) (9)(2) Open Actes:

\begin{abstract}
SODIS (Solar Water Disinfection) is an alternative to traditional methods of water disinfection and consists of exposing under the sun containers filled with water to be disinfected. This research aims to check SODIS efficiency in the representative context of riverine communities which use rainwater for drinking. The analysis included turbidity, $\mathrm{pH}$, temperature, E. coli and total coliforms (MPN/100ml). The samples were raw water at $0 \mathrm{~h}$; after 6 hours of sun exposure; and water 24 hours after the use of SODIS for identifying bacterial regrowth. We conducted an experiment on sunny and cloudy days, analyzing the base supporting the bottles and half-face painted bottles. We obtained the following results: a) the experiment conducted in sunny day decreased from 4 to $0 \mathrm{NMP} / 100 \mathrm{ml}$ coliform bacteria and E. coli, resulting in $100 \%$ inactivation, without regrowth after 24 hours; the temperature was $55^{\circ}$ $\mathrm{C}$ on average and maximum of $57^{\circ} \mathrm{C}$ in bottles painted with half face black; b) on cloudy day SODIS decreased total coliforms and E. coli from 4 to $0 \mathrm{NMP} / 100 \mathrm{~mL}$ after 6 hours of exposure; the temperature was $45^{\circ} \mathrm{C}$ and maximum $47^{\circ} \mathrm{C}$ in painted bottles. The results indicated that the metal surface had no positive influence on the water temperature; the $\mathrm{pH}$ remained on average 7.3; Turbidity was 2UNT. We concluded that the SODIS method is effective for the household treatment of rainwater.
\end{abstract}

Keywords: Rainwater, Amazonas, Tefé, SODIS, solar water disinfection

\section{Tratamento de água da chuva com SODIS para comunidades ribeirinhas}

\section{RESUMO}

SODIS (Solar Water Disinfection) é uma alternativa aos métodos tradicionais de desinfecção da água e consiste em expor ao sol recipientes preenchidos com água a ser desinfetada. A presente pesquisa verificou a eficiência da SODIS no contexto representativo das comunidades ribeirinhas, que utilizam água de chuva para consumo. Os experimentos foram realizados na sede do Instituto Mamirauá em Tefé-Amazonas. As análises incluíram turbidez, $\mathrm{pH}$, temperatura, E. coli e coliformes totais (NMP/100 $\mathrm{mL}$ ). As amostras coletadas foram: água bruta às $0 \mathrm{~h}$; após $6 \mathrm{~h}$ de exposição ao sol; e água após $24 \mathrm{~h}$ do uso da SODIS, para identificação de recrescimento bacteriano. Realizaram-se um experimento em dia de céu aberto e céu nublado, analisando-se a superfície de apoio das garrafas e a pintura de meia-face das garrafas de cor preta. Obteve-se como resultados: a) o experimento realizado em céu aberto apresentou redução de 4 para <0,3NMP/100 mL de coliformes e ausência de E.coli após 6 horas de exposição da água ao sol, resultando em $100 \%$ de inativação, não havendo recrescimento após $24 \mathrm{~h}$; a temperatura teve média $55^{\circ} \mathrm{C}$ e máxima de $57^{\circ} \mathrm{C}$ nas garrafas pintadas com meia face de preto; b) em dia de céu nublado houve redução de coliformes totais e $E$. coli de 4 para $<0,3 \mathrm{NMPNMP} / 100 \mathrm{~mL}$ após $6 \mathrm{~h}$ de exposição; a temperatura média foi $45^{\circ} \mathrm{C}$ e máximo de $47^{\circ} \mathrm{C}$ nas garrafas pintadas de preto. Os resultados indicaram que a superfície de metal não teve influência positiva na temperatura da água; o pH manteve-se em média 7,3; a turbidez perto de 2UNT. Conclui-se que o método SODIS é eficiente para o tratamento domiciliar da água da chuva.

Palavra-Chave: Águas pluviais, Ribeirinhas, Desinfecção Solar, SODIS.

\section{INTRODUÇÃO}

O uso da energia solar para tratamento de água vem sendo testado em diversas pesquisas ao passo que a sua utilização vem acontecendo mais notadamente em países em desenvolvimento ou em áreas rurais e isoladas quando não existe nenhum tratamento de água para população dessas localidades.

Diante desse cenário, surgiram alternativas de tratamento de água partindo dos métodos convencionais, ao passo que os desinfetantes 
químicos que tratam a água têm permitido melhora na qualidade de vida e diminuição da mortalidade infantil por doenças entéricas, com uma eficiência sem precedentes na história [1]. Porém, alguns desinfetantes podem gerar subprodutos prejudiciais à saúde e esta geração dependerá do controle da qualidade da água, do seguimento desinfecção e há rejeição ao consumo de água com cloro [2]. A [3] SODIS é um tratamento de água domiciliar que assim como a fervura busca a eliminação total de bactérias nocivas à saúde com um diferencial: a energia utilizada nesse método é natural da combinação de raios UV e temperatura provenientes da energia solar.

Nesse sentido, as comunidades ribeirinhas do médio Solimões onde estão localizadas as Reservas de Desenvolvimento Sustentável Mamirauá e Amanã (RDSM e RDSA) vêm sendo acompanhadas pelo Instituto Mamirauá em oficinas sobre os tratamentos de água existentes, como cloração, fervura e ainda a tecnologia SODIS, (sendo o último um tratamento fácil de ser aplicado e que em comunidades como as das Reservas é viável já que existe a dificuldade de acesso à água com qualidade). Além disso, segundo o último Censo Demográfico realizado pelo Instituto de Desenvolvimento Sustentável Mamirauá nas Reservas as garrafas PET aparecem em segundo lugar como os recipientes mais usados pelas famílias para armazenar água para o consumo, demonstrando que existe grande potencial para o uso do SODIS [4]. Diante dos expostos acima, a presente pesquisa teve como objetivo estudar a eficiência da desinfecção solar no contexto representativo das comunidades ribeirinhas, onde foi possível verificar a eficiência do método para o tratamento da água de

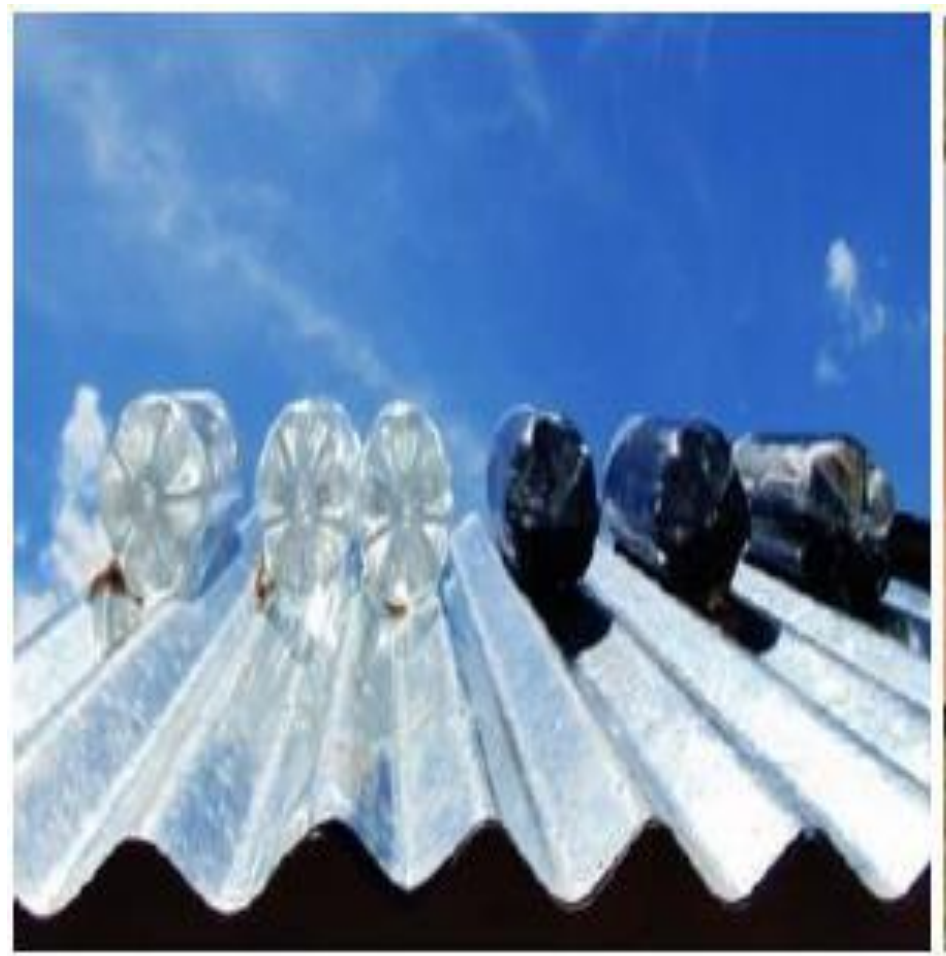

do tratamento, do tempo de contato, do $\mathrm{pH}$, temperatura, etc.

Uma alternativa de desinfecção por agentes físicos é a utilização da energia solar. Reconhecida mundialmente por meio da tecnologia SODIS, testada em diversas pesquisas, é aplicável aos usuários individuais quando não existem sistemas públicos de

consumo, através de experimentos que levaram em consideração a qualidade da água disponível e o clima da região.

\section{MATERIAIS E MÉTODOS}

A água da chuva foi coletada na sede do Instituto Mamirauá, a partir do telhado do estacionamento e armazenada em uma caixa d'água de 500 litros. Após a coleta de água ela ficava depositada nessa caixa e passava por um tempo de decantação antes de se utilizar nos experimentos. Para o transporte da água até o laboratório foram usados dois galões de água mineral de 20 litros, higienizados nolaboratório.

As análises da qualidade da água incluíram turbidez, $\mathrm{pH}$, temperatura, além de Escherichia coli e coliformes totais com a Técnica Miniaturizada para identificação do Número Mais Provável de micro-organismos por $100 \mathrm{~mL}$ (NMP/100 mL). As amostras coletadas foram: água bruta às $0 \mathrm{~h}$; após $6 \mathrm{~h}$ de exposição ao sol; e água após $24 \mathrm{~h}$ do uso da SODIS, para identificação de recrescimento bacteriano. Realizaram-se dois experimentos: um experimento em dia de céu aberto (Figura 1) e um em dia de céu nublado. Analisou-se ainda a superfície de apoio das garrafas e a pintura de meia-face das garrafas de cor preta (garrafas pintadas e garrafas não pintadas), teve-se um total de 12 garrafas e 1 controle (garrafa sem exposição ao sol).

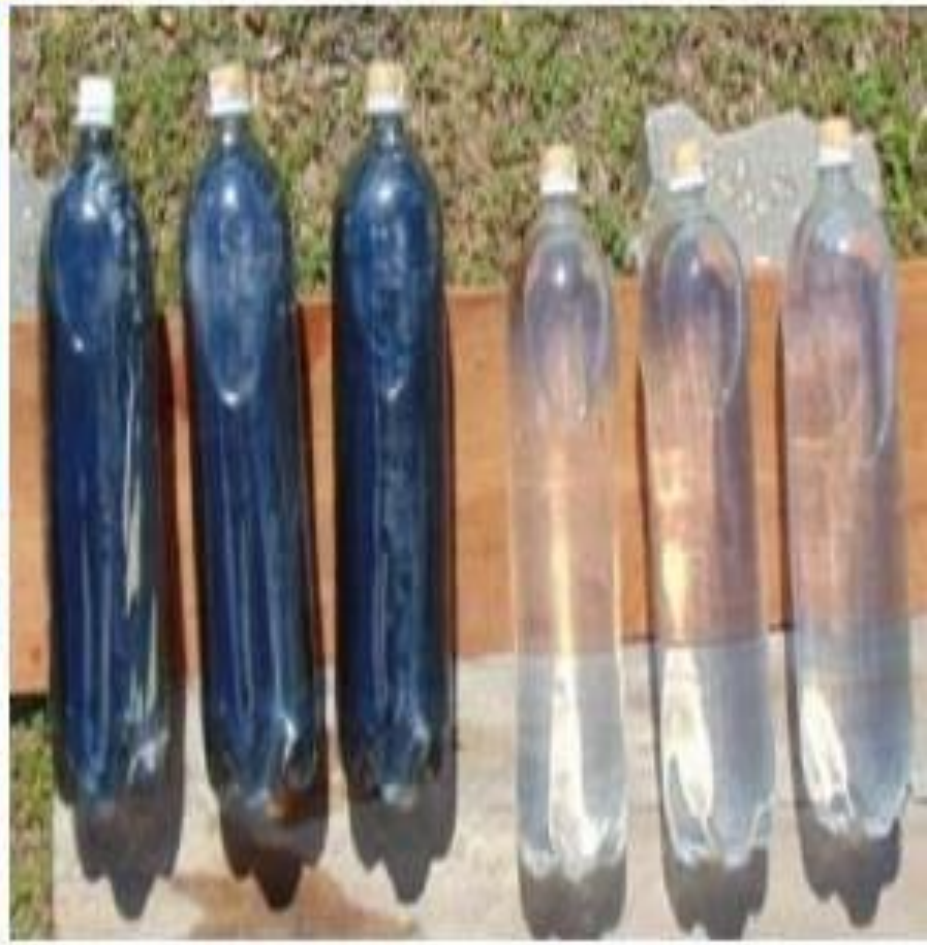

Figura 1: Experimentos de desinfecção solar de água de chuva: superfície de metal na imagem da esquerda e superfície de madeira na imagem da direta.

Fonte: Autores, (2016).

Para ratificar a eficiência do método utilizamos uma garrafa controle (garrafa sem exposição ao sol) com a amostra no mesmo tempo de exposição das garrafas no sol $(6 \mathrm{~h})$, isso proporcionou a verificação da crescimento/decrescimento de bactérias na água sem o uso do método SODIS [5].
Para verificar se houve diferença estatística significativa dos resultados de temperatura e concentração de coliformes totais durante os experimentos foram realizadas análises de variância não paramétrica de Kruskall-Wallis [6]. 


\section{RESULTADOS E DISCUSSÃO}

Apresenta-se os resultados da variação de temperatura na Figura 2.

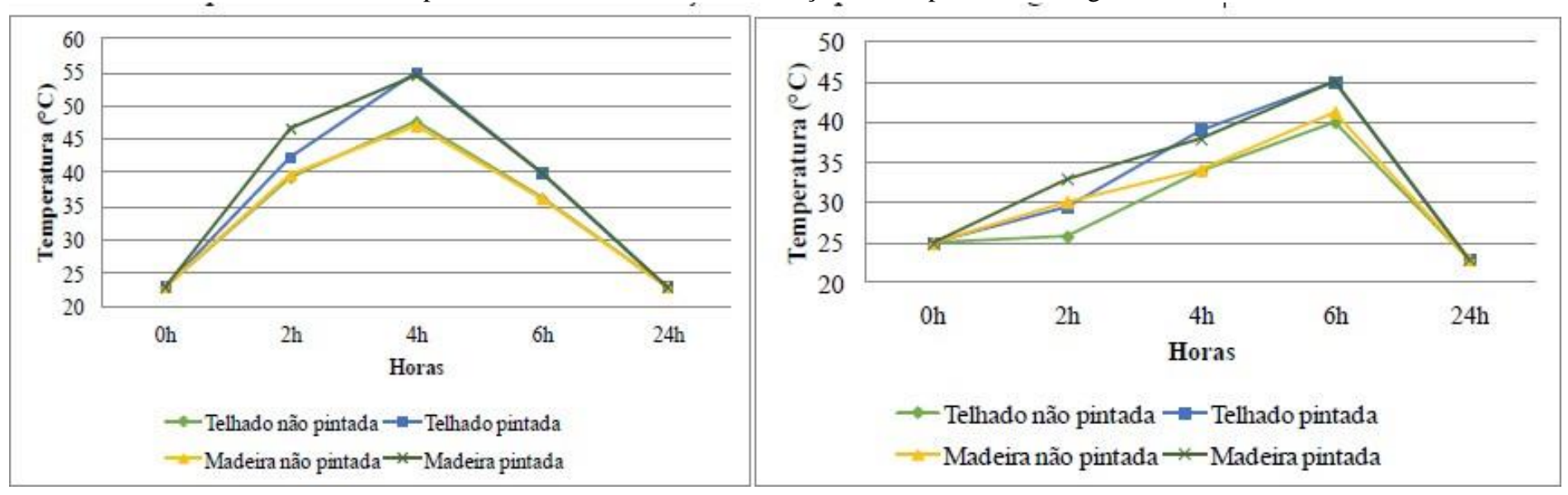

Figura 2: Temperatura média nos horários de exposição ao sol em dia ensolarado (esquerda) e nublado (direita).

Fonte: Autores, (2016).

No experimento realizado em condição ambiental de céu aberto apresentou redução de $4 \mathrm{NMP} / 100 \mathrm{~mL}$ para $<0,3 \mathrm{NMP} / 100$ $\mathrm{mL}$ de coliformes e ausência de $E$. coli após $6 \mathrm{~h}$ de exposição ao sol, portanto resultando em $100 \%$ de inativação, não havendo recrescimento após $24 \mathrm{~h}$ do uso do método. Os valores de temperatura chegaram em média a $55^{\circ} \mathrm{C}$ e tiveram máxima de $57^{\circ} \mathrm{C}$ nas garrafas pintadas com meia face de preto; foi verificada a presença de E. coli e coliformes apenas na garrafa que não foi exposta ao sol (garrafa controle) indo de $9 \mathrm{NMP} / 100 \mathrm{~mL}$ no tempo de $6 \mathrm{~h}$ para 23NMP/100 mL após $24 \mathrm{~h}$ de armazenamento da água nessa garrafa.

No experimento realizado em dia de céu nublado houve inativação de coliformes totais e $E$. coli de $4 \mathrm{NMP} / 100 \mathrm{~mL}$ na amostra bruta para <0,3NMP /100 mL após 6h de exposição; neste dia verificou-se a presença desses microrganismos apenas na garrafa controle, indo de 9NMP/100mL para $150 \mathrm{NMP} / 100 \mathrm{Ml}$ após $24 \mathrm{~h}$ do armazenamento da água nessa garrafa (que não foi exposta ao sol). Em dia nublado, registrou-se os valores de temperatura em média igual a $45^{\circ} \mathrm{C}$ e máximo de $47^{\circ} \mathrm{C}$ nas garrafas pintadas de preto.

Os resultados indicaram que a superfície de metal não teve influência positiva na temperatura da água, uma vez que a superfície de madeira aumentou a temperatura $5^{\circ} \mathrm{C}$ a mais que a superfície de metal, sendo, portanto, mais eficiente que a reflexiva. $\mathrm{O}$ pH manteve-se em média 7,3 não havendo variação durante o processo;

A turbidez da água de chuvanão influenciou no processo de desinfecção durante os ensaios e manteve-se por volta de 2UNT, ou seja, quanto às analises físico-química a água estava dentro do padrão ( $\mathrm{pH}$ entre 6 e 9, turbidez até 5UNT) de potabilidade estabelecido pela Portaria ${ }^{\circ} 2.914$ do Ministério daSaúde.

A análise de variância Kruskal-Wallis resultou em valor de $\mathrm{p}<0,05$, ou seja, houve diferença estatística significativa nas comparações dos resultados de temperatura e concentração de coliformes totais antes e depois da exposição ao sol, comprovando a eficácia da tecnologia.

\section{CONCLUSÕES}

Diante dos resultados obtidos, chega-se às seguintes conclusões: as garrafas pintadas tiveram maiores valores de temperatura em ambos os experimentos; houve inativação total de E. coli em todos os experimentos; a superfície de madeira foi mais eficiente para o aumento de temperatura da água nas garrafas, em oposição à superfície de metal; a turbidez encontrada na água da chuva foi baixa e por esse motivo não impediu a inativação de $E$. coli e coliformes totais, e ainda foi possível confirmar a eficiência da desinfecção da água com as análises de controle que apresentaram recrescimento bacteriano. Com isso verificou-se a eficiência do método para o tratamento da água da chuva para uso domiciliar.

\section{REFERÊNCIAS}

[1] Daniel, L. A. (coordenador). Processos de Desinfecção e Desinfetantes Alternativos na Produção de Água Potável. PROSAB II tema I. Rima: São Carlos, 2001.

[2] Martín-Domínguez, A.; Alarcón-Herrera, T.; MartínDomínguez, I.; González-Herrera, A. Efficiency in the disinfection of water for human consumption in rural communities using solar radiation. Solar Energy, 2005.

[3] SODIS: MANUAL DE TREINAMENTO PARA DIVULGAÇÃO DO SODIS. Dubendorf: EAWANG; SANDEC, (Report No.13/06), 35 p. 2006.

[4] Gomes, M. C. R. L; Nascimento, A. C. S.; Corrêa, D. S. S.; Moura, E. A. F. Condições De Uso Da Água EmComunidades Das Reservas De Desenvolvimento Sustentável Mamirauá E Amanã Em 2010. Livro de Resumos do $\mathbf{1 0}^{\circ}$ Simpósio sobre Conservação e Manejo Participativo na Amazônia. Tefé, 2013.

[5] Paterniani, J. E. S. e Silva, M. J. M. Desinfecção de efluentes com tratamento terciário utilizando energia solar (SODIS): avaliação do uso do dispositivo para concentração dos raios solares. Revista Engenharia Sanitária e Ambiental, 2005.

[6] Ayres, Manoel. Elementos de Bioestatística: A seiva do açaizeiro. Belém, 2010. 